\title{
MATERIALISM AND AGGRESSIVE DRIVING: AN ISRAELI STUDY
}

Kalanit Efrat, Ruppin Academic Center, Israel Aviv Shoham, University of Haifa, Israel

\begin{abstract}
Aggressive driving is a growing problem that has been identified as a major risk factor for car accidents. Previous research has provided some insights about the characteristics of drivers prone to aggressiveness on the road, as well as external triggers of road aggressiveness. However, little is known of the personality traits of aggressive drivers. This study employs the theory of planned behavior (TPB) to consider the role of materialism in aggressive driving, and particularly its three source traits: envy, possessiveness, and non-generosity. Our findings show that envy and non-generosity have an impact on aggressive driving.
\end{abstract}

